\title{
Implant complications in bruxism patients
}

\author{
Ji-Young Song \\ Department of Dentistry, School of Medicine, Jeju National University, Jeju, Korea
}

\begin{abstract}
J Korean Assoc Oral Maxillofac Surg 2021;47:149-150)
Bruxism is defined as a parafunctional activity during sleep or while awake that includes locking and grinding of teeth and clenching. It generates excessive occlusal force that may lead to implant failure. Therefore, diagnosis of bruxism and providing specific protocols such as occlusal splint and/or injection of botulinum toxin before implant installation are important to prevent increases the risk of implant failure in bruxism patients.
\end{abstract}

Key words: Bruxism, Dental implants, Implant-supported dental prosthesis, Dental prosthesis failure

[paper submitted 2021. 3. 29 / accepted 2021. 3. 29]

\section{Introduction}

Bruxism is defined as monotonous masticatory muscle activity characterized by clenching and grinding of teeth and/ or thrusting of mandible either in sleep or while awake. It is a common parafunctional habit that leads to overloading of the masticatory muscles and temporomandibular problems ${ }^{1-3}$.

Bruxism has been reported to have a positive association with implant complications ${ }^{1,2,4}$. Therefore, the purpose of this study is to evaluate the assessment of bruxism and to discuss the ways of reducing implant complications in patients with bruxism on the basis of literature review.

\section{Implant Complications Related to Bruxism}

Implant complications are divided into early and late failures. Early failures are related to osseointegration and late failures are related to occlusal overload ${ }^{5,6}$.

Bruxism is related to the late failures such as implant fracture, screw loosening, screw fracture, fracture of prosthesis

\section{Ji-Young Song}

Dental Clinic, Jeju National University Hospital, 15 Aran 13-gil, Jeju 63241, Korea

TEL: +82-64-717-1840

E-mail:2460song@naver.com

ORCID: https://orcid.org/0000-0002-9500-6557

(c) This is an open-access article distributed under the terms of the Creative Commons Attribution Non-Commercial License (http://creativecommons.org/ licenses/by-nc/4.0/), which permits unrestricted non-commercial use, distribution, and reproduction in any medium, provided the original work is properly cited. Copyright (C) 2021 The Korean Association of Oral and Maxillofacial Surgeons. All rights reserved. (ceramic or porcelain), severe marginal bone loss and decementation $^{4,7}$. The failure rate is increased by intensity and frequency of excessive occlusal forces on dental implants due to bruxism. The direction of parafunctional forces affects the survival rate of implants and implant-supported prosthesis?

\section{Assessment of Bruxism}

Diagnosis of bruxism is complicated. The assessments of bruxism can be divided into non-instrumental and instrumen$\mathrm{tal}^{3}$.

\section{Non-instrumental assessments}

Non-instrumental assessments include clinical inspection and self-reporting such as by filling questionnaires.

Clinical features of bruxism include hypertrophy of the masticatory muscles with linea alba on the intraoral cheek and/or indentation on the lip or tongue. Severe masticatory muscle pain or temporomandibular joint pain, extreme mechanical tooth wear (attrition) and complications of prosthesis may also be indicative of bruxism. Mechanical tooth wear is differentially diagnosed from chemical tooth wear caused by gastro-esophageal reflux. Attrition due to past bruxism that is not currently active is ruled out carefully during the assessment of current bruxism ${ }^{3,4}$.

Self-reports may reveal muscle and joint pain resulting from psychological conditions such as stress and anxiety. However, self-report have limitations because they might not 
reflect actual hyperactivity of masticatory muscles ${ }^{3}$.

Presently, non-instrumental assessments are not complete methods for diagnosis of bruxism. However, they may provide a good rationale for performing instrumental assessments $^{3,4}$.

\section{Instrumental assessments}

Instrumental assessments are currently the most accurate way to evaluate bruxism. However, they are time-consuming and are associated with extra costs.

During the awake state, electromyographic monitoring may provide key evidence for awake bruxism, whereas polysomnographic monitoring during sleep is regarded as a gold standard for evaluating sleep bruxism ${ }^{3,4}$.

\section{Treatments of Bruxism}

The most commonly used method to treat bruxism is occlusal splint. It has been used to prevent mechanical tooth wear and to attenuate pain in masticatory muscles. Occlusal splint is a non-invasive treatment ${ }^{1}$. Its use distributes the occlusal force, resulting in favorable prognosis for dental implants and prostheses $^{8}$. Injection of botulinum toxin into the masticatory muscles may be another option to treat bruxism. The effect of botulinum toxin is that it decrease muscle strength and mastication and thus reduces excessive parafunctional force to the tooth and temporomandibular joint ${ }^{9}$.

\section{Editor's Opinion}

The correlation between bruxism and implant failure is still controversial. However, many studies have reported the positive association bruxism with implant complications ${ }^{3-5,7,8}$. Therefore, based on these reports, a specific protocol needs to be implemented before implant installation to prevent increases the risk of implant failure in bruxism patients.

Sufficient history taking such as experience of repetitive prosthesis failures and of nocturnal bruxism and careful clinical inspection of the evidence of bruxism are necessary before implant surgery. If you find such evidence by using non-instrumental and/or instrumental assessment, sufficiently explain to the patients that bruxism increases the risk of implant failure and emphasize the recommendation of an additional treatment such as occlusal splint and/or injection of botulinum toxin.

\section{Author's Contributions}

The manuscript was written by J.Y.S.

\section{Conflict of Interest}

No potential conflict of interest relevant to this article was reported.

\section{References}

1. Lavigne GJ, Khoury S, Abe S, Yamaguchi T, Raphael K. Bruxism physiology and pathology: an overview for clinicians. $\mathrm{J}$ Oral Rehabil 2008;35:476-94. https://doi.org/10.1111/j.13652842.2008.01881.x

2. Lobbezoo F, van der Zaag J, van Selms MK, Hamburger HL, Naeije M. Principles for the management of bruxism. J Oral Rehabil 2008;35:509-23. https://doi.org/10.1111/j.1365-2842.2008.01853.x

3. Lobbezoo F, Ahlberg J, Raphael KG, Wetselaar P, Glaros AG, Kato $\mathrm{T}$, et al. International consensus on the assessment of bruxism: report of a work in progress. J Oral Rehabil 2018;45:837-44. https:// doi.org/10.1111/joor.12663

4. Yu HC, Kim YK. Fractures of implant fixtures: a retrosccepective clinical study. Maxillofac Plast Reconstr Surg 2020;42:13. https:// doi.org/10.1186/s40902-020-00258-3

5. Albrektsson T, Donos N; Working Group 1. Implant survival and complications. The third EAO consensus conference 2012. Clin Oral Implants Res 2012;23 Suppl 6:63-5. https://doi.org/10.1111/ j.1600-0501.2012.02557.x

6. Manfredini D, Poggio CE, Lobbezoo F. Is bruxism a risk factor for dental implants? A systematic review of the literature. Clin Implant Dent Relat Res 2014;16:460-9. https://doi.org/10.1111/cid.12015

7. Chitumalla R, Halini Kumari KV, Mohapatra A, Parihar AS, Anand KS, Katragadda P. Assessment of survival rate of dental implants in patients with bruxism: a 5-year retrospective study. Contemp Clin Dent 2018;9(Suppl 2):S278-82. https://doi.org/10.4103/ccd. ccd_258_18

8. Tosun T, Karabuda C, Cuhadaroglu C. Evaluation of sleep bruxism by polysomnographic analysis in patients with dental implants. Int J Oral Maxillofac Implants 2003;18:286-92.

9. Fernández-Núñez T, Amghar-Maach S, Gay-Escoda C. Efficacy of botulinum toxin in the treatment of bruxism: systematic review. Med Oral Patol Oral Cir Bucal 2019;24:e416-24. https://doi. org/10.4317/medoral.22923

How to cite this article: Song JY. Implant complications in bruxism patients. J Korean Assoc Oral Maxillofac Surg 2021;47:149150. https://doi.org/10.5125/jkaoms.2021.47.2.149 